\title{
How Expert Designers Design
}

\author{
Citation for published version (APA):
}

Kirschner, P. A., Carr, C., Van Merriënboer, J., \& Sloep, P. (2002). How Expert Designers Design. Performance Improvement Quarterly, 15(4), 86-104. https://doi.org/10.1111/j.1937-8327.2002.tb00267.x

DOI:

10.1111/j.1937-8327.2002.tb00267.x

Document status and date:

Published: 01/12/2002

Document Version:

Peer reviewed version

Please check the document version of this publication:

- A submitted manuscript is the version of the article upon submission and before peer-review. There can be important differences between the submitted version and the official published version of record. People interested in the research are advised to contact the author for the final version of the publication, or visit the DOI to the publisher's website.

- The final author version and the galley proof are versions of the publication after peer review.

- The final published version features the final layout of the paper including the volume, issue and page numbers.

Link to publication

\section{General rights}

Copyright and moral rights for the publications made accessible in the public portal are retained by the authors and/or other copyright owners and it is a condition of accessing publications that users recognise and abide by the legal requirements associated with these rights.

- Users may download and print one copy of any publication from the public portal for the purpose of private study or research.

- You may not further distribute the material or use it for any profit-making activity or commercial gain

- You may freely distribute the URL identifying the publication in the public portal.

If the publication is distributed under the terms of Article 25fa of the Dutch Copyright Act, indicated by the "Taverne" license above, please follow below link for the End User Agreement:

https://www.ou.nl/taverne-agreement

Take down policy

If you believe that this document breaches copyright please contact us at:

pure-support@ou.nl

providing details and we will investigate your claim.

Downloaded from https://research.ou.nl/ on date: 26 Apr. 2023 
Running head: HOW DESIGNERS DESIGN

How Expert Designers Perceive Design: Priorities in Designing Competence-Based Learning Environments

\author{
Paul Kirschner ${ }^{1}$ \\ Chad Carr ${ }^{2}$ \\ Jeroen van Merriënboer ${ }^{1}$ \\ Peter Sloep $^{1}$
}

Correspondence concerning this article should be addressed to Paul A. Kirschner, Open University of the Netherlands, Educational Technology Expertise Center (OTEC), P.O. Box 2960, NL-6401 DL Heerlen, The Netherlands. E-mail may be sent to paul.kirschner@ou.nl

1 Open University of the Netherlands Arthur Andersen 


\begin{abstract}
Two studies were carried out with expert educational designers at Arthur Andersen and the Open University of the Netherlands to determine the priorities they say that employ when designing competence-based learning environments. Designers in a university context and in a business context agree almost completely on what principles they feel are important, the most important being that one should start a design enterprise from the needs of the learners, instead of the content structure of the learning domain. The main difference between the two groups is that university designers relate that they find it extremely important to consider alternative solutions during the whole design process; something that business designers report as being considerably less important. University designers say that they focus more on project plan and desired characteristics of the instructional blueprint whereas business designers report being more client-oriented, stressing the importance of "buying in" the client early in the process.
\end{abstract}




\section{How Expert Designers Design}

In both business training and higher professional education there is a clear shift towards competency-based learning to cope with fast technological and societal changes. Competencies can be construed as abilities that enable learners to recognize and define new problems in their domain of study and - future - work as well as solve these problems (Kirschner, van Vilsteren, Hummel, \& Wigman, 1997). Acquired competencies enable learners to apply these skills and attitudes in a variety of situations (transfer) and over an unlimited time span (lifelong learning) (van Merriënboer, 1999).

Approaches to competency-based learning share a constructivist view on learning. Amongst other things, they stress independent learning in rich information environments, authentic learning tasks, and negotiation of meaning by taking multiple perspectives.

Constructivism is not an approach to or model for instruction, but rather a philosophy of learning based on the idea that learners are active in constructing their own understanding of the world. It proves to be hard to make this "golden dream" operational: Most teachers and designers are struggling with the current paradigm shift from knowledge-oriented teaching to competencybased learning (Le Maistre, 1998; Moallem, 1998)

Gero (1997) states that "Given the large body of research design it is surprising how little we know about designing” (p. 61). Although prescriptive models for the design of competencybased learning environments are beginning to appear (e.g., van Merriënboer, 1997), no fullfledged, practical Instructional Design (ID) models are yet used by practitioners. Consequently, designers' implicit cognitive strategies and rules-of-thumb heavily influence the design process (Rowland, 1995). While there have been a number of articles on what software designers do, or say that they do (e.g., Hooker, 1992; McPhee, 1997), this article is unique in that it is the start of 
a project designed to find out what instructional designers actually do when designing competency-based learning environments. The results will be useful to a further development of ID-models. The main research questions are:

- How do instructional designers, in their own eyes and words, say that they design competency-based learning environments?

- Which cognitive strategies and heuristics ("rules of thumb") affect the design process?

- How can this knowledge be used for improving Instructional Design models for competency-based learning?

This article begins with a discussion of constructivist design and design principles.

Second, a review of studies on instructional design practices is presented, focusing on the actual use of instructional design strategies and heuristics by designers. Third, the preliminary findings of two empirical studies on design behaviors are presented. Both studies emphasized the design of competency-based learning environments. Finally, the discussion emphasizes the implications of our research findings for the further development of ID-models for competency-based learning.

\section{A Major Shift in Instructional Design}

In educational circles, designers are moving from cognitive, often rule based instructional design for efficient and effective teaching towards constructivist instructional design for competency-based learning. The problem is that this is not a question of adaptation of the design methodology used, but is a question of beginning anew.

The traditional cognitivist paradigm used by educational institutions is the teaching/learning paradigm. Curricula are subject matter oriented and are organized as such. They are divided into courses on specific areas of expertise, often the result of a combination of 
historical factors (This was the way I learnt it), a clinical analysis of the - so-called - structure of a domain or discipline (This is the 'objective' hierarchy of the subject matter) and analysis of the expertise of the teachers (Professor $\mathrm{X}$ is an expert in ...). The acquisition of learning is assessed through traditional assessment methods (knowledge tests, essay tests, individual term papers and theses, et cetera). Traditional designers first attempt to analyze content and prerequisites to identify a course sequence.

Constructivist designers "know" that content cannot be pre-specified. Although a certain amount of content may be available for students to use, they are encouraged to seek out as many alternate sources of knowledge as they can find to deepen their perspective of the topic they are working on. Here, the notion of situated learning is important. Students are encouraged to consider what practitioners in a particular (authentic) professional or working environment would do. Traditional theory focused on the typical learner and what he or she would know when the course was completed. A constructivist learner is not described. Instead, through metacognition, all learners are encouraged to reflect on how and what they are learning and how it fits into what they already know. Traditional theory specifies objectives for knowledge acquisition in advance. Constructivism attempts to identify the culture of a knowledge domain.

The synthesis or design phase of traditional instruction involves the design of a sequence and message to achieve specified performance objectives. Pre-specified content and objectives are not congruent with a constructivist worldview. Substituted for these activities would be: learning based on situated cognition in (electronic) learning environments that more or less mimic real world contexts; cognitive apprenticeship and modeling; and negotiation of meaning through collaborative learning emphasizing multiple perspectives of analysis. Another emphasis in constructivism is to make available an array of cognitive tools that can scaffold the learner 
within this rich, sometimes confusing, environment. In electronic learning environments, this refers to computer-based tools.

\section{A beginning of an ID-model based on constructivism}

Some general aspects of designing education/educational environments according to constructivist theories (Wilson, Teslow \& Osman-Jouchoux, 1995) are:

- $\quad$ Apply a holistic/systemic design model that considers instructional factors (e.g., learner, task, setting) in increasing detail throughout the development process. Rather than doing a learner or task analysis once early in the process, return to these factors and their interactions continuously through the project cycle (e.g., Wilson, Teslow, \& OsmanJouchoux, 1993).

- $\quad$ Consider solutions that are closer to the performance context (e.g., job aids, just-in-time training, performance support systems). This is consistent with situated models of cognition and with the notion of distributed cognition (Perkins, 1993).

- Use objectives as heuristics to guide design. Don't always insist on operational performance descriptions that may constrain the learners' goals and achievement. The 'intent' of instruction can be made clear by examining goal statements, learning activities, and assessment methods. Goals and objectives should be specific enough to serve as inputs to the design of assessments and instructional strategies.

- Don't expect to capture the content in your goal or task analysis. Content on paper is not the expertise in a practitioner's head. The best analysis always falls short of the mark. The only remedy is to design rich learning experiences where learners can pick up on their own the content missing between the gaps of analysis. 
- Give priority to problem solving and constructing learning goals. Instead of rule following, emphasize problem solving (which incorporates rule following, but is not limited to it). Instead of simple recall tasks, let learners make sense out of material and demonstrate their understanding of it.

- $\quad$ Allow for multiple goals for different learners. Hypermedia and collaborative work learning environments almost - by definition - are designed to accommodate multiple learning goals. Even within traditional classrooms, technologies exist today for managing multiple learning goals (Collins, 1991).

- $\quad$ Consider teaching models based on the constructivist paradigm such as cognitive apprenticeship, minimalist training, intentional learning environments, and case- or storybased instruction. Seek out instructional strategies and systems that use authentic problems in collaborative, meaningful learning environments (see Wilson \& Cole, 1991b).

- Consider strategies that provide multiple perspectives and that encourage the learner to exercise responsibility. Resist the temptation to "pre-package" everything. Let learners generate their own questions or presentation forms.

\section{C-ID design model for competency-based learning}

An example of a comprehensive instructional design model that takes a cognitiveconstructivist starting point and explicitly aims at the development of competency-based education is van Merrienboër's four-component instructional design model (4C/ID; 1997). The model focuses on real-life tasks as the driving force for learning (cf., Clark \& Estes, 1999; van Merriënboer \& Kirschner, 2001). The general assumption is that such tasks help learners to integrate the knowledge, skills and attitudes necessary for effective task performance; give them the opportunity 
to learn to coordinate constituent skills that make up complex task performance, and eventually enables them to transfer what is learned to their daily life or work settings. A basic assumption of the 4C/ID model is that environments for complex learning can be described in terms of the learning tasks, supportive information, just-in-time information, and part-task practice. Figure 1 shows a schematic view on the four components.

\section{INSERT FIGURE 1 ABOUT HERE}

\section{What the Literature Says that Instructional Designers Actually Do}

It is now clear what the gurus of instructional design over the past eight decades say that instructional designers should do. But what do they actually do? There appears to be a clear difference between designing instruction as a practical activity and ID (Rowland, 1993). While ID-models often inspire designers, their activities typically don't reflect the systematic, step-bystep approach as prescribed in traditional ID-models. Systemic, zigzag or even chaotic design activities can frequently be observed - especially for expert designers (Rowland, 1992). Krabbe (1998), in a study of what curriculum developers do, notes that standardization (the use of a method), professional practice and curriculum development are related to each other in such a way that tensions arise between the professional practices of curriculum designers and the standard methods that are available to them. Analog to this, a similar relationship may exist with respect to design of competency-based learning environments.

For design of competency-based learning environments based on constructivist assumptions no full-fledged ID-models are yet available. Especially for such design enterprises, implicit strategies and rules-of-thumb will heavily influence the design process (see, e.g., 
Rowland, 1995). Krabbe (1998) cites one of her subjects as follows: "Curriculum developers use creativity as an excuse not to use an instrument when carrying out their work". We define creativity here as making use of one's professional knowledge and skills 'above and beyond' the constraints of the model used to design learning environments. One of the main aims of this project is to find out what instructional designers actually do when designing competency-based learning environments. This will offer a first knowledge base that may help to develop empirical guidelines for the design of electronic, competency-based learning environments.

To provide a context for our study, we will provide an overview of instructional design followed by a review of the relevant studies of instructional design practice.

\section{What is instructional design?}

Instructional design (ID) comprises the ideas, plans and rules of what has to be done or could be done in order to develop instruction, that is, the explanations and assignments to promote learning and reach a learning outcome that is described in advance. Instruction is an activity intended to promote learning (i.e. the acquisition of knowledge, skills or attitudes). ID is not only a set of heuristic structures that give a solution to an instructional design problem, but the underlying theory of an ID-model should also describe the different types of knowledge and skills and how instructions influence the acquisition of knowledge and skills and how these are transferred for future use (Dijkstra et al, 1997)).

There are two types of theories that are relevant to ID, namely descriptive theories and prescriptive theories. Descriptive theories help explain the results obtained from using a given method under certain conditions. They give the guidelines for an ID-model, as an instrument, that helps the designer with designing. Rowland refers to these theories as "explaining what designers do." (Rowland, 1993) Prescriptive theories rely on continuous evaluation of their 
application to improve both the ID-model and the underlying instructional theory. Rowland refers to these as "what designers should do." (Rowland, 1993)

The goal of this study is to study design practice, especially the strategies and heuristics expert-designers say that they use. Rowland (Rowland, 1992) suggests that the ID literature generally discusses what designers should do (prescriptive), rather than reflecting upon empirically based studies of what designers actually do (descriptive). The exception would be a study by Kerr (1983) in which 26 instructional designers were given a design task and were interviewed afterward to determine what they actually did during the task. Results of this and other relevant studies will be discussed in the next section.

Currently, there are no full-fledged prescriptive ID-models available for the design of competency-based learning environments. This (descriptive) study of design practice can be an instrumental first step in providing an understanding of what designers of competency-based learning environments actually do.

The following section provides a review of the literature describing what designers do. First, we summarize the key findings of the literature over the past twenty years. Then, we review the results of design heuristics, a designer's frame of reference and the strategies of Visscher-Voerman (Visscher-Voerman, 1999).

Review of the use of instructional design strategies

Designers differ in the amount of expertise they demonstrate (Le Maistre, 1998). There are differences in the design approach of novices versus experts (Rowland, 1992;Perez \& Emery, 1995), but there is also a significant amount of variation between experts (Rowland, 1992).

Designers who use prototypes and heuristic knowledge seem to have found an alternative to 
carry out the steps present in complete prescriptive design models (Winer \& Vazquez-Abad, 1995).

From the results of the descriptive studies of instructional designers (IDs), it is evident that instructional designers, in practice, design highly solution-driven, context-sensitive solutions through an iterative and integrative process. Rowland (1992), Visscher-Voerman, (1999), Pieters and Bergman (1995), and Perez and Emery (1995) agree that experts design in a solutiondriven way. Le Maistre (Le Maistre, 1998) concludes that a more iterative design approach will be more productive in giving instructional designers the basic strategies needed for their practice. Rowland (Rowland, 1992) and Perez and Emery (Perez \& Emery, 1995) describe the solutiondriven strategy as one where experts, having explored the problem and interpreting it as illdefined, first make use of solution ideas to constrain the analysis, and then make use of a variety of interventions such as experiences, templates and design principles for the problem solution. That it is an integrative process means that designers combine and incorporate various design activities at the same time. For example, designers simultaneously explore the solution while specifying the problem (Visscher-Voerman, 1999). Also, expert designers conduct repeated cycles of try-out and improvement as an iterative way of designing (Winer \& Vasquez-Abad, 1995). These different approaches are not rule driven, but rather the result of a number of interacting factors in the direct design context which influence the kind of actions or choices designers make (Visscher-Voerman, 1999).

Further, instructional designers selectively choose ID-model prescriptions. In most design projects, deviations and discrepancies from the general instructional systems design model occur as design practitioners selectively follow ID-model prescriptions (Wedman \& Tessmer, 1993). The amount of available time and money highly impacts which activities designers choose to 
conduct or omit. Lack of time is the most reported reason for not completing a design activity (Wedman \& Tessmer, 1993) with pilot testing and establishing the need for training most often being omitted. Winer and Vasquez-Abad (Winer \& Vazquez-Abad, 1995) conclude that designers de-emphasize conducting a thorough analyses less (task analysis; needs assessment) while placing more emphasis on repeated cycles of tryout and improvement. Pieters and Bergman (Pieters \& Bergman, 1995) conclude that these discrepancies from the general instructional systems design model relate to the practical context of working and that designers spend less time than strictly needed for prototype design and evaluation.

Instructional designers also emphasize the importance of communication with stakeholders and users. Pieters and Bergman (Pieters \& Bergman, 1995) found that it is important to know how open stakeholders and users are to a variety of potential solutions. By doing this, designers can get an idea as to whether the implementation of a solution is feasible. In this context, Klimczak and Wedman (Klimczak \& Wedman, 1997) advise designers to be sensitive to the possibility that they do not share the same priorities as other stakeholders, such as teachers/trainers, sponsors and learners.

Instructional designers differ in expert performance. The descriptions of expertcharacteristics given by Chi (Chi et al, 1988), Shanteau (Shanteau, 1992), and Le Maistre (Le Maistre, 1998) suggest that some instructional designers may be characterized as expert. As such they make use of expert characteristics such as superior content knowledge, ability to simplify complex problems, ability to handle adversity, constant adjustment of decisions, and decomposition of a problem into manageable parts.

Finally, the instructional designers' theoretical background (or frame of reference) influences the design process and solution. Based on an in-depth case study of 24 designers, 
Visscher-Voerman (Visscher-Voerman, 1999) determined that this frame of reference influences the way of designing and focuses the instructional designers' approach. Her research question was "What design strategies do professional high-reputation designers use in practice in various training and education contexts?" The designers were, in her approach, defined as the case and the unit of analysis. Interviewing designers about their design approach by focusing on a project recently finished was used as a way to invite them to illustrate and embed their statements in a concrete document. Her dissertation resulted in a framework including four design paradigms of professionals, recommended design principles, and a discussion of promising design strategies.

\section{Designers' heuristics according to Visscher-Voerman}

Visscher-Voerman (Visscher-Voerman, 1999) distilled 16 design principles from her case analyses (see Table 1). She then reduced this number to the 11 principles where there was at least a $75 \%$ positive agreement of the expert-designers (the non-shaded principles). In our empirical study - described in the following section - the full list of 16 was used.

The 11 remaining design principles correspond largely to the strategies found in the other literature. Pieters and Bergman (Pieters \& Bergman, 1995) recognize that designers should have consideration for stakeholders and users. Visscher-Voerman also emphasizes that designers should not forget the important role and influence of clients, users and other stakeholders early in and during the design process and use their tactics to involve them. (see principle $3,5,6,7,8$, and 9). In principle 6, she advises the re-use of design products, for example by showing earlier products as a tactic to explain and a helpful means to participate, or to reach consensus, or create ownership with stakeholders. 


\section{INSERT TABLE 1 ABOUT HERE}

\section{Summary of Research Findings}

Table 2 presents a summary of published research on how instructional designers design.

\section{INSERT TABLE 2 ABOUT HERE}

From an analysis of the research we can conclude that instructional designers:

- thoroughly explore and interpret the problem,

- $\quad$ consider a wide range of possible solutions and a wide range of factors, combining them and use context knowledge,

- $\quad$ should take more time for prototyping and evaluation,

- $\quad$ use a highly interactive and collaborative design approach (cooperation with stakeholders) (goal is anticipate on implementation and reach consensus),

- view designing as a social process and find it important to communicate with users and stakeholders,

- $\quad$ believe that areas as availability of tangible resources, implementation support and training strategies contribute to project success,

- differ in amount of expertise and in expert performance, and

- $\quad$ contribute in some- not clarified- way to project success. 


\section{Empirical Study of Expert Designers}

\section{Experiment 1}

A first, qualitative empirical study with expert designers was carried out to determine the priorities of expert designers and what they report to be their actual approach to design.

\section{Method}

Participants. Participants are expert instructional designers $(N=15)$ from the Open University of the Netherlands (OUNL; $N=9$ ) and Arthur Andersen $(N=6)$. The OUNL is a distance education institution dedicated to competence based university education. It is known for both its high quality educational materials and its innovative approach to education and its design.

Arthur Andersen, at the time this research was being carried out, was a leading global professional services firm that helped clients find ways to create, manage and measure value and to succeed in the new economy. The Andersen Learning and Personal Growth organization was the firm's resource for learning, education and performance enhancement and support.

Materials. The participants were required to determine their top three design principles from the Visscher-Voerman list of 16 design principles. The exact task was to determine the design principles "that are most important to the success of a design project". After having done this, they were required to determine from that same list their top three design principles that "need the most improvement".

Procedure. The research took place in Heerlen, The Netherlands. The participants, located in Heerlen, The Netherlands and St. Charles, IL, USA worked independently of each other to evaluate the design principles. After having done this, the rating sheets were collected and the results were tabulated. Finally, the results were discussed to eliminate misconceptions. 
The discussion was carried out with the aid of real-time videoconferencing. One of the researchers moderated the experiment.

\section{Results and Discussion}

Table 3 gives the results with respect to design principles that the expert designers say (1) are most important to the success of a design project and (2) need the most improvement. Responses were shared from the OUNL and Arthur Andersen. The numbers correspond to the Sixteen Design Principles listed in Table 1.

\section{INSERT TABLE 3 ABOUT HERE}

The first conclusion that can be drawn from this experiment is that the expert designers in this study are in agreement with those in the Visscher-Voerman study with respect to the design principles. Of the principles found to be either important or needing improvement, only two were on the list of discarded principles from Visscher-Voerman (principles 4 and 8) and these were only named by the designers at the OUNL, many of whom are not only active as designers but also as researchers.

With respect to the designers at the OUNL, most consider principles 13 and 5 (starting from learner needs and consideration of alternative possible solutions) to be the most important. The remaining five important principles $(1,2,3,4,7)$ pertain to a split between the process (prototyping, phasing) and respect for the needs of the stakeholders. Interesting here is that of the principles found to be most important according to the participants, three also need the most improvement according to them $(3,4,13)$. 
With respect to the designers at Arthur Andersen, four principles are given as being most important $(1,3,7,13)$. Specifically, the designers at Arthur Andersen felt it was critical to gain buy in from clients through the early sharing of prototypes. Further, they believed that starting with the needs of the learners was critical to creating an effective learning solution. Interesting also at Arthur Andersen, as was the case at the OUNL, two of the four principles judged to be most important also are said to need improvement (7 and 13).

With respect to the total group, both Arthur Andersen and the OUNL agree almost completely with respect to what principles are important, namely principles $1,2,3,7$, and 13 . The only principle on which they did not agree was also the most important principle according to the OUNL participants, namely the search for alternative solutions (principle 5). This difference could be the result of a combination of factors, namely that OUNL designers are also often researchers and the OUNL is not a commercial institution so that deadlines are never very 'hard' and thus divergence is more possible than at an institution such as Arthur Andersen. With respect to what principles need improvement, the two institutions are also fairly well in agreement.

\section{Experiment 2}

\section{Method}

Participants. The participant were the same as in Experiment 1: expert instructional designers $(N=15)$ from the Open University of the Netherlands (OUNL; $N=9$ ) and Arthur Andersen $(N=6)$.

Materials. The design task was to make a preliminary design for a post-graduate program in environmental consulting for a consulting firm. The designers were supplied with a three page description of the task with respect to (1) a description of the field of environmental consultancy, 
(2) the high level generic competencies of an environmental consultant, (3) the goal of the consulting firm with respect to their need for training/education of their staff and (4) a competency map for the program. The competency map consisted of three units of competence (Acquisition, Project Planning, Project Supervision) with their constituent elements of the competence and performance criteria. An example of an element from the competence unit 'Acquisition' is "Stay on top of new developments in the content field, particularly those that concern the firm's core competencies." An example of a performance criterion for this element is: "Report (for instance to the firm's knowledge management system) new developments in the environmental field, particularly those in his own area of expertise." The competency map could be read in the following way: "A person competent with respect to $<$ unit of competence>, has to $<$ element $>$; a person who is able to $<$ element $>$, will $<$ performance criterion $>$."

For the design activity, the teams made use of an Action-Object Worksheet to outline the steps that the team would take to design a course. An action refers to something that designer would do to design the course; an object refers to something the designer would use to complete that particular action. As an example for the action: "Review data about students' performance to understand their skill/knowledge level", the defined objects were: "student SAT scores" and "student GPAs". After completion of the task, the design teams were required to present their top two actions to the group (with an explanation) and hand in their complete Worksheets.

One of the major reasons why this object-action approach was chosen and why we made use of a paper and pencil Object-Action Worksheet is that this approach forms the precursor of an electronic version of such an instrument which in development at the OUNL and that will be used for the same purpose in the future. This instrument will eventually yield a multi-level representation of designers' cognitive goals as action-object pairs, or, a layered representation of 
object-action matrices (Elkerton \& Palmiter, 1991). For instance, cognitive goals at the highest level are represented by the actions 'explore', 'analyze' and 'design' and the objects 'target group', 'context', and 'task'. At the second level, each cell is further specified in a lower-level action-object matrix, et cetera. Thus, the tool allows us to specify all "action-object" combinations used by the designers as well as the order in which particular combinations are used.

Procedure. The participants were divided into design teams of two or three persons each (OUNL, 3 teams; Arthur Andersen, 2 teams). The teams were given 90 minutes to carry out the design task described above.

\section{Results and Discussion}

Although designers at the two institutions were fairly unanimous about what they consider to be the principles involved in good design (the theory), the way they approached the design task showed a definite difference between the institutions. The OUNL first carefully mapped out the task by conducting a task analysis of expert environmental consultants. Team 1 chose to first carry out a detailed task analysis (mapping the systematic approaches to problem solving used by experts) followed by the generation of learning tasks. Team 2 chose the same beginning, namely making an inventory of the tasks an expert normally carries out (but with a novel approach, namely the Woolgar and Latour (1975) technique of anthropological study of expert environment consultants) followed by the generation of learning tasks with their concomitant assessment criteria. Team 3 stated that their first step would be the production of a project plan for approval by the client, but in order to produce this plan, the designer would need to define the problem, analyze the population, determine discrepancies in terms of knowledge / skills, list constraints, and globally sequence the learning tasks. 
Arthur Andersen took a more client-oriented approach, first gaining "buy-in" from the client up front, showing examples of successful projects as concrete examples. Team 4 chose to first do a general needs-assessment, followed by the creation of a buy-in from key stakeholder of work yet to be performed. Their approach to the needs-assessment entailed first acting as a detective (beginning with a hunch / hypothesis and then validating straw man), and then discussing / burning / adapting the straw man based upon focus groups and observation. In order to create a buy-in, they chose to treat the sponsors and stakeholders as novice designers by showing them what is successful / what works and then confronting them with examples of other possibilities and models. Team 5 took a slightly more analytical approach, opting for the determination of best practice (complex, non-recurrent competencies) within organizational policy (how are things addressed within the organizational infrastructure) to arrive at an objective or competency map. This would then be followed by a target audience analysis via interviews and focus groups.

\section{General Discussion}

While competency-based education is becoming more and more popular, neither descriptive nor prescriptive instructional design models focusing on this type of instruction have yet been fully developed. The main purpose of the research reported in this article was to make a first step towards determining how competency-based education actually is developed and which strategies and heuristics experienced designers use. This approach (of first determining what designers say that they do, and then determining what they actually do with the help of an automated Object-Action instrument) will hopefully provide useful input for the further development of dedicated ID-models and tools for designing and developing competency-based learning environments. Although constructivism is consistent with new types of learning, there 
are no full-fledged, constructivist design models available. This is true for prescriptive models as well as descriptive models; that is, we know very little about how designers actually develop competency-based instruction according to a (social) constructivist framework.

Previous research on how designers actually design was reviewed in the beginning of this article. This research has shown that designers (1) design in an iterative fashion highly solutiondriven, context-sensitive solutions, (2) make a very selective choice of ID-model prescriptions, (3) emphasize the importance of communication with stakeholders and users, (4) greatly differ in expert performance, and (5) are influenced by their theoretical background or frame of reference. In addition, 16 heuristics or design principles that were identified by Visscher-Voerman (1999) were briefly reviewed. Overall, the studies indicated that there is a clear gap between the ID process as described in prescriptive instructional design models and the process as it is performed in the real world. Here, it should be noted that these studies mainly compared instructional design behaviors with prescriptive ID-models that were rooted in a behaviorist or cognitivist tradition.

In contrast, our empirical studies pertained to professional designers who develop competency-based education within a constructivist framework. But roughly speaking, their design strategies were in agreement with those described by Visscher-Voerman (1999). Furthermore, professional designers in a university context and in a business context agree almost completely with respect to what principles are important, the most important heuristic stating that one should start a design enterprise from the needs of the learners, instead of the content-based structure of the learning domain. The main difference between the two groups is that designers at a university find it extremely important to consider alternative solutions during the whole design process; something that is not rated as being important by designers in a 
business context. This difference might be well explained as a cultural difference between academia and business. In the second experiment, the differences between the two contexts became even more obvious. University designers tended to focus on the project plan and the desired characteristics of the instructional blueprint; business designers were much more clientoriented and stressed the importance of "buying in" the client early in the process.

Major limitations of our studies concern their generalizability. First, this concerns our target groups. The university designers and business designers not only operated in other contexts (university vs. business), but also in other countries. While the way instructional designers are educated is very similar between the United States and the Netherlands, with the same instructional theories and models taught in the major educational ID programs, our findings may nevertheless have been influenced by cultural differences between both countries.

Furthermore, one may wonder if our findings may be generalized to design tasks that not concern competency-based education, are of a longer duration, or are in other respects different from the tasks used in the current studies.

Future research should thus clearly aim at a replication of our findings for other groups of designers than used in this study (e.g., European business designers, United States university designers); design tasks that are not directed towards competency-based education (e.g., for dual learning, distance teaching, etc.), and tasks of a longer duration that not only include analysis and design, but also development of materials, implementation and evaluation. Furthermore, a more complete model of design activities that are relevant for competency-based education would allow researchers not only to focus on what designers do, but also on what they not do, that is, how they prioritize. Eventually, future research should develop detailed-descriptive and prescriptive - models of how instructional designers set priorities for complex design projects. 
The data that have been gathered in our experiments are currently being analyzed further. A top-down, breadth-first expansion of methods and goals (as known from the actionobject matrices) has been made. High-level methods that designers use to decompose the initial design task into a sequence of subtasks have been identified; intermediate methods that describe the sequence of functions necessary to complete a subtask, and low level methods that generate the actual actions necessary to perform a function have been identified. Some methods pop up that - a majority of - designers say that they use to reach particular goals in the design of authentic learning tasks and support structures in competency-based learning environments. These methods will form the basis for an ID-model that is directed toward the development of competency-based education. The present study indicated clear differences between what designers actually do and what they "should" do according to current design methodologies, as well as differences between university designers and business designers. It is thus clear that a useful design model for competency-based education should take contextual differences and designers' priorities into account in order to profitably help to design effective and appealing learning environments. 
References

Chi, M. T. H., Glaser, R., \& Farr, M. J. (1988). The nature of expertise, Lawrence Erlbaum Associates, Hillsdale, NJ.

Collins, A. (1988). Cognitive apprenticeship and instructional technology. Eric Document \# ED 331465

Dijkstra, S., Schott, F., Seel, N. M., \& Tennyson, R. D. (1997). Instructional Design: International Perspectives, volume 1 Theory, Research and Models. Lawrence Erlbaum Associates, Publishers. Mahwah, New Yersey and London, England.

Elkerton, J., \& Palmiter, S. L. (1991). Designing help using a GOMS model: An information retrieval evaluation. Human Factors, 33, 185-204.

Gero, J. S. (1997). What are we learning from designers and its role in future CAAD tools. In R. Junge (Ed.), CAADFutures (pp. 61-70). Dordrecht, The Netherlands: Kluwer.

Hooker, J. N. (1992). Is design theory possible??. Technical report, Engineering Design Research Center, Carnegie Mellon University.

Hoogveld, A. W. M., Paas, F., Jochems, W. M. G., \& van Merriënboer, J. J. G. (20020. Exploring teachers' instructional design practices from a design perspective. Instructional Science, 30, 291-305.

Kerr, S. T. (1983). Inside the black box: Making design decisions for instruction. British Journal of Educational Technology, 14, 45-58.

Kirschner, P. A., Vilsteren, P. van, Hummel, H. \& Wigman, M. (1997). A study environment for acquiring academic and professional competence, Studies of Higher Education, 22(2), $151-171$. 
Klimczak,A. K. \& Wedman,J. F. (1997). Instructional Designer's decisions and priorities: A survey of design practice. Educational Technology Research and Development, 45, 7583.

Krabbe, E. (1998). Tussen intuïtie en rationaliteit [Between intuition and rationality]. Doctoral dissertation, University of Twente, Enschede.

Le Maistre, C. (1998). What is an expert instructional designer? Evidence of expert performance during formative evaluation. Educational Technology, Research and Development, 46, 21-36.

Moallem, M. (1998). An expert teacher's thinking and teaching and instructional design models and principles: An ethnographic study. Educational Technology, Research and Development, 46, 37-64.

Perez, R. S. \& Emery, C. D. (1995). Designer thinking: how novices and experts think about instructional design. Performance Improvement Quarterly, 8, 80-95.

Perkins, D. (1991). Technology meets constructivism: Do they make a marriage? Educational Technology, 31(5), 18-23.

Pieters, J. M. \& Bergman, R. (1995). The empirical basis of designing instruction. Performance Improvement Quarterly, 8, 118-129.

Rowland, G. (1992). What do instructional designers actually do? An initial investigation of expert practice. Performance Improvement Quarterly, 5(2), 65-86.

Rowland, G. (1993). Designing and instructional design. Educational Technology, Research and Development, 41(1), 79-91.

Rowland, G. (1995). Instructional design and creativity: A response to the criticized. Educational Technology, 35(5), 17-22. 
Shanteau, J. (1992). The psychology of experts: An alternative view. In G. Wright \& F. Bolger (Eds.) Expertise and decision support. pp. 11-23. Plenum Press, New York.

Van Merriënboer, J. J. G. (1997). Training complex cognitive skills. Englewood Cliffs, NJ: Educational Technology Publications.

Van Merriënboer, J. J. G. (1999). Cognition and Multimedia Design. Open Universiteit Nederland.

Visscher-Voerman, J. I. A. (1999). Review of Design in Theory and Practice. Universiteit Twente.

Wedman, J. F. \& Tessmer, M. (1993). Instructional Designers' Decisions and Priorities. A survey of Design Practice. Performance Improvement Quarterly, 6, 43-57.

Wilson, B., \& Cole, P. (1991). A review of cognitive teaching models. Educational Technology Research and Development, 39 (4), 47-64.

Wilson, B., Teslow, J., \& Osman-Jouchoux, R. (1993). What does a constructivist ID-model look like? A makeover of traditional ID based on constructivist and postmodern ideas. In E. E. Smith \& J. G. Smith, (Eds.), Building Partnerships '93: Bridging technology, performance, and development (pp. 64-74). Breckenridge, CO: American Society for Training and Development.

Winer, L. R. \& Vazquez-Abad, J. (1995). The present and future of ID practice. Performance Improvement Quarterly, 8, 55-67. 


\section{List of figures}

Figure 1. The relationship between standardization, professional practice and curriculum development.

Figure 2. A schematic representation of blueprints developed according to the 4C/ID model. 
Figure 1

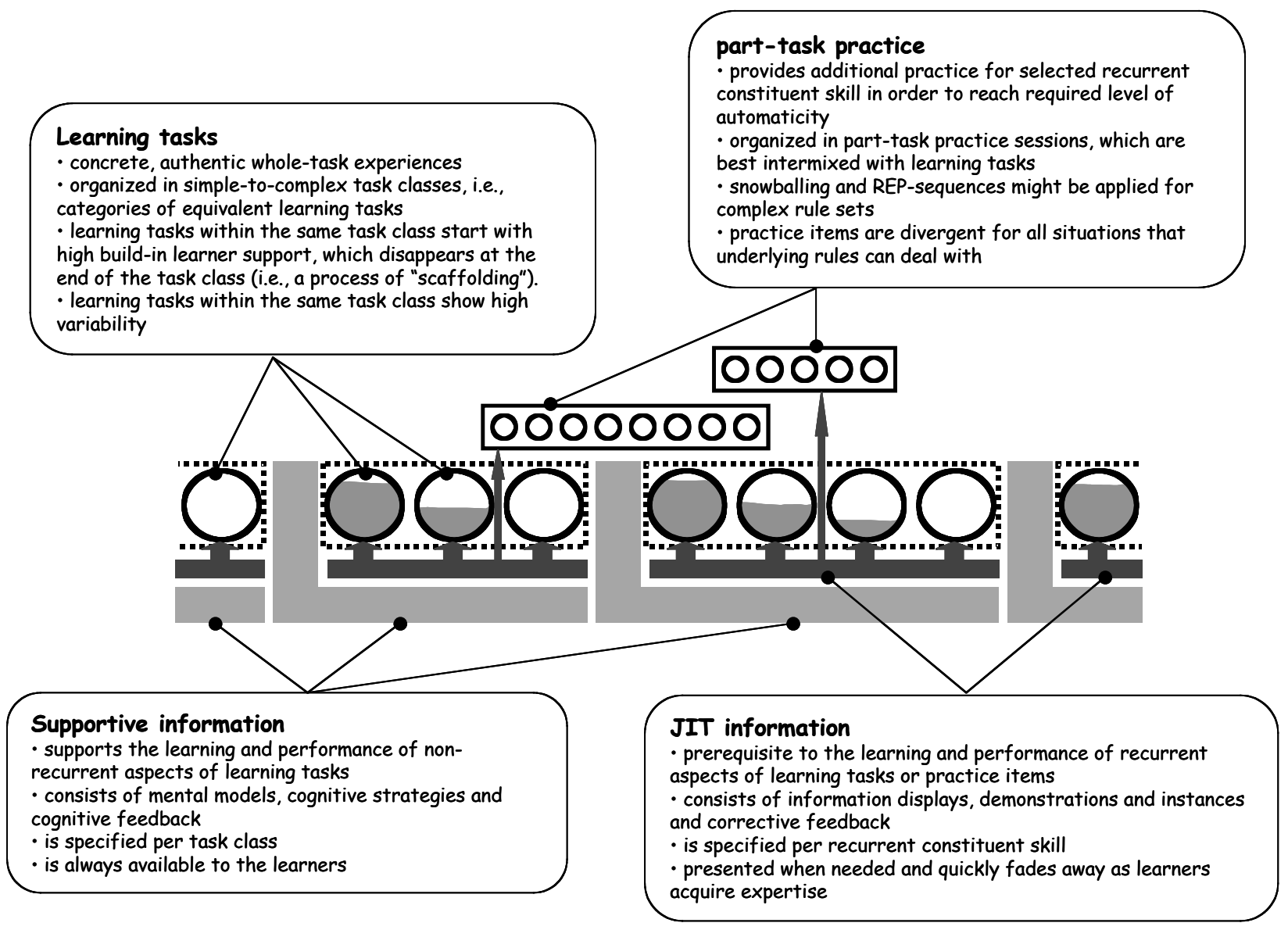


Table 1. Sixteen design principles from Visscher-Voerman (1999)

1. Designers should make a prototype in an early stage of the design process.

2. Designers should split the design process into phases with formal decision moments and concrete products, and should only plan the upcoming phase in detail.

3. During the design process, designers should pay as much attention to creating ownership with clients and stakeholders, as to reaching theoretical or internal quality of the design.

4. Designers should base their work in scientific knowledge and principles as much as possible.

5. Even if designers have a clear idea for the (potential) solution at the start of the process, consideration of possible altemative solutions is essential.

6. Designers should not only ask clients and (future) users for content-related input, but should also give them the right to decide about the design itself.

7. A useful means to help clients, partners, and other stakeholders to choose a solution and to formulate product specifications is by showing products from former projects.

8. In order to clarify product specifications, designers should spend their time on carefully planned formative evaluations of early versions of a prototype, rather than on an elaborate preliminary analysis.

9. Designers should share the responsibility for creating favorable conditions for the implementation of a design.

10. For efficient and effective formative evaluations, several (about three) sources and several (about three) data gathering instruments should be used.

11. The creativity and artistic skills of the designer should be clearly visible in the final product.

12. Designers should ask those with an important role in the development and implementation for their early participation in the design activity.

13. While making an educational design, designers should start from the needs of the leamers, rather than from the content-based structure.

14. Designers should conduct formative evaluations themselves.

15. Successful design is served by the use of step-by-step schemes and design models, provided that they are adapted.

16. An essential part of the analysis phase is a consideration of possible pitfalls and problems during the design and implementation phases. 

Table 2. Review of research describing instructional design practice

\begin{tabular}{|c|c|c|c|}
\hline Researchers & Objectives & Method & Key Findings \\
\hline Kerr (1983) & $\begin{array}{l}\text { To determine: } \\
\text { - the prevalence of initial generation } \\
\text { of more than one possible design } \\
\text { solution } \\
\text { - the basis on which candidate } \\
\text { solutions were accepted or rejected } \\
\text { - the constraints encountered in } \\
\text { proceeding with the design } \\
\text { - the way in which designers knew } \\
\text { that they were finished with the } \\
\text { design }\end{array}$ & $\begin{array}{l}\text { - } \mathrm{N}=26 \text { Novice instructional } \\
\text { designers } \\
\text { - Graduate students completed a } \\
\text { design task and were } \\
\text { interviewed afterward about } \\
\text { their process and decisions }\end{array}$ & $\begin{array}{l}\text { - } 69 \% \text { of novice designers selected from more than one } \\
\text { possible design solution } \\
\text { - } 38 \% \text { used their own experience to determine which } \\
\text { candidate design solution was best } \\
\text { The most common constraint mentioned by novice } \\
\text { designers is Difficulties in specifying objectives } \\
\text { /outcomes ( } 35 \% \text { ) } \\
\text { - } 54 \% \text { determined a stopping point in the design process } \\
\text { when all objectives were dealt with }\end{array}$ \\
\hline $\begin{array}{l}\text { Le Maistre } \\
(1998)\end{array}$ & $\begin{array}{l}\text { - To identify differences in novice } \\
\text { and expert thinking }\end{array}$ & $\begin{array}{l}\text { - } \mathrm{N}=2 \text { ( } 1 \text { expert and } 1 \text { novice } \\
\text { designer) } \\
\text { - Think aloud during revision of } \\
\text { instruction, interviews to } \\
\text { debrief and clarify outcomes }\end{array}$ & $\begin{array}{l}\text { Expert designers: } \\
\text { - have a rich, well organized knowledge base of } \\
\text { instructional design } \\
\text { - represent problems at a deep level } \\
\text { - perform extensive front-end analysis } \\
\text { - search the problem space rapidly and efficiently } \\
\text { - have excellent self-monitoring skills } \\
\text { Note: Results were compared to and confirmed a study of } \\
\text { expertise by Glaser and Chi (1988) }\end{array}$ \\
\hline $\begin{array}{l}\text { Perez \& } \\
\text { Emery } \\
(1995)\end{array}$ & $\begin{array}{l}\text { - To identify differences in novice } \\
\text { and expert thinking } \\
\text { - To describe a cognitive model of } \\
\text { design }\end{array}$ & $\begin{array}{l}\text { - } \mathrm{N}=4 \text { expert designers who } \\
\text { were extensively interviewed } \\
\text { - } \mathrm{N}=9 \text { designers who were asked } \\
\text { to think aloud during a design } \\
\text { activity }\end{array}$ & $\begin{array}{l}\text { - Novices and experts use divergent design paths } \\
\text { - Experts spend more time exploring the problem } \\
\text { - Novices identify the design problem } \\
\text { - Experts interpret the design problem } \\
\text { - Experts consider a wide range of factors in combination } \\
\text { with one another }\end{array}$ \\
\hline
\end{tabular}




\section{Pieters \& Bergman (1995)

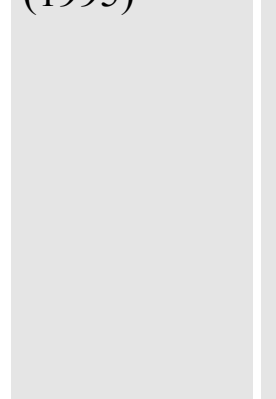 \\ Rowland \\ (1992) \\ - Determine what happens during instructional design \\ - Determine differences between expert vs. novice}

- $\mathrm{N}=35$ graduates from University of Twente, The Netherlands

- Survey distributed to 120 current practitioners 35 responded

- $\mathrm{N}=8$ novice and expert designers

- Think-aloud during a design activity
- Deviations and discrepancies of the general Instructional Systems Design model occur

- Discrepancies relate to practical context of working

- Less time than needed for prototype design and evaluation

- Integrated design with fluid boundaries between phases and activities within phases follow an iterative process

- Designers should realize in advance how open intended users or other stakeholders are to a variety of potential solutions

Novice designers:

- interpret the problem as well-defined

- make little analysis

- quickly move to solution generation

- use instruction for solution

- use learner-experiences as internal resources

- make decisions based on single, local factors

Expert designers:

- interpret a problem as ill-defined

- make a lengthy analysis

- use solution ideas to constrain analysis

- use a variety of interventions for the solution

- use experiences, templates and design principles as internal resources

- base decisions on multiple, global factors

- do not delay solution attempts ( $80 \%$ rule)
Visscher-

Voerman (1999)
- To describe strategies that designers use in practice

- To specify why they deviate from their general project approach
- $\mathrm{N}=24$ expert designers

- Interviews were conducted

\section{Expert designers:}

- commonly use examples from previous projects

- perceive evaluation activities to be important

- develop from an implementation perspective 
- To determine what factors forced them to conduct alternative activities

Wedman \&

Tessmer

- To determine if and how designers (1993) include design activities in projects

- $\mathrm{N}=73$ designers / developers

- Survey was conducted from members of mid-west, USA NSPI chapter

- $\mathrm{N}=66$ designers / developers

- Survey was conducted from members of Canadian NSPI chapter

- Replication of Wedman and Tessmer (1993)
- design strategies are highly solution-driven, iterative, integrative and context-sensitive

- Sixteen Design Principles

- Design practitioners selectively follow ID-model prescriptions

- Lack of time and money is most often the reason for not completing a design activity

- Activities of pilot testing and establishing need for training are most often omitted

- Call for increased use of pilot testing

- Designers perform more frequently those design steps judged as most important

- Prototyping is emerging as an alternative to development of complete prescriptive models

- Less emphasis on conducting thorough analyses (task analysis, needs assessment) more emphasis on repeated cycles of tryout and improvement

- Designers are moving toward the design of learnercentered learning environments 
Table 3. Most important and improvable design principles (in approximate order of importance)

\begin{tabular}{lll}
\cline { 2 - 3 } & OUNL & Arthur Andersen \\
\hline Important & $\underline{13}, 5,1,2, \underline{3}, \underline{4}, \mathbf{7}$ & $1,3, \underline{7}, \underline{13}$ \\
Needs Improvement & $\underline{3}, \underline{4}, \underline{13}$, & $5, \underline{7}, \underline{13}, 16$ \\
\hline
\end{tabular}

$\underline{\text { Underline }}=$ Requires immediate attention to improve (most important and needs improvement) 
Prof. dr. Paul Kirschner is Professor of Educational Technology at the Educational Technology Expertise Center (OTEC) at the Open University of the Netherlands, Professor of Contact and Distance Education at the Faculty of General Sciences/Knowledge Engineering at Maastricht University, and member of the Educational Council of the Netherlands. He studied Psychology at the State University of New York at Stony Brook (BA, 1973), Educational Psychology at the City University of Amsterdam (MA, 1978) and received his Ph.D. from the Open University of the Netherlands in 1991.

His research interests include design, delivery and assessment of competency-based higher education, affordances in CSCL environments, and innovation of higher education.

\author{
Mailing address: \\ Prof. dr. P.A. Kirschner \\ Open University of the Netherlands \\ Educational technology Expertise Center \\ PO Box 2960 \\ 6401 DL Heerlen \\ The Netherlands
}

